\title{
GESTÃO ADAPTATIVA DE PROJETOS: UM LEVANTAMENTO DOS ARTEFATOS MAIS UTILIZADOS PARA GERENCIAR O ESCOPO DO PROJETO
}

\author{
ADAPTIVE PROJECT MANAGEMENT: \\ A SURVEY OF THE MOST USED ARTIFACTS TO MANAGE THE PROJECT SCOPE
}

\author{
Danilo Rabetti \\ Mestre em Gestão de Negócios \\ Faculdade FIA de Administração e Negócios \\ São Paulo, SP - Brasil \\ drabetti@yahoo.com.br \\ Ivete Rodrigues \\ Doutora em Administração pela FEA/USP \\ Professora da Faculdade FIA de Administração e Negócios \\ São Paulo, SP - Brasil \\ iveter@fia.com.br
}

Resumo

Os objetivos da pesquisa são (a) mapear os artefatos de gerenciamento de escopo preconizados pelos métodos preditivos e ágeis; (b) verificar quais deles têm sido utilizados pelos gerentes de projetos e suas organizações; e c) identificar e analisar o uso da abordagem adaptativa de gerenciamento de projetos em função da complexidade do projeto. Foi consolidado, com base na revisão da literatura, um conjunto de artefatos tradicionais e ágeis para gerenciamento de escopo do projeto. Em seguida, foi utilizado o método de levantamento para verificar quais artefatos são mais utilizados pelos gerentes de projetos tendo em vista a complexidade dos projetos. Os resultados apontaram que os gerentes de projetos, em sua maioria, ainda não têm flexibilidade na escolha dos artefatos utilizados nos projetos. Os artefatos preditivos são os mais utilizados, mas há indícios de que as empresas começam a migrar para uma abordagem adaptativa. $\mathrm{O}$ estudo oferece uma contribuição acadêmica quanto à consolidação dos artefatos disponíveis para o gerenciamento de escopo de um projeto, tanto na corrente tradicional quanto na corrente ágil. Também contribui no levantamento dos artefatos que estão realmente em uso, no sentido de melhor se entender como é a feita a escolha dos artefatos, independentemente de abordagens metodológicas únicas. Quanto às implicações gerenciais, os resultados poderão contribuir com a prática das empresas, auxiliando-as a decidir sobre o uso de técnicas e artefatos para gerenciamento de escopo existentes em ambas as abordagens, evitando utilizar indiscriminadamente as metodologias ágeis ou se manter enraizados nos controles e planos das metodologias tradicionais.

Palavras-chave: Gerenciamento de projetos. Métodos ágeis. Método preditivo. Complexidade em projetos. Gestão adaptativa de projetos. Gestão híbrida de projetos. Gestão de escopo de projetos.

\begin{abstract}
The paper objectives are (a) to map the scope management artifacts recommended by predictive and agile methods; (b) verify which of them have been used by project managers and their organizations; and c) identify and analyze the use of the adaptive project management approach according to the project complexity. Based on the literature review, a set of traditional and agile artifacts for project scope management was consolidated. Then, the survey method was used to verify which artifacts are most used by project managers in view of the complexity of the projects. The results showed that the majority of project managers still do not have flexibility in choosing the artifacts used in the projects.
\end{abstract}


Predictive artifacts are the most used, but there are indications that companies are beginning to migrate to an adaptive approach. The study offers an academic contribution to the consolidation of the artifacts available for managing the scope of a project, both in the traditional and in the agile methodologies. It also contributes to analyses the artifacts that are actually in use, in order to better understand how the choice of artifacts is made, regardless of unique methodological approaches. In terms of managerial implications, the results may contribute to the companies' practice, helping them to decide on the use of techniques and artifacts for scope management in both approaches, avoiding using the agile methodologies indiscriminately or remaining rooted in the controls and plans of traditional methodologies.

Keywords: Project management. Agile methodology. Predictive methodology. Project complexity. Adaptive project management. Hybrid project management. Scope project management.

\section{Cite como - American Psychological Association (APA)}

Rabetti, D., \& Rodrigues I. (2021, Ed. Esp. jan./abr.). Gestão adaptativa de projetos: um levantamento dos artefatos mais utilizados para gerenciar o escopo do projeto. Revista de Gestao e Projetos (GeP), 12(1), 95-122. https://doi.org/10.5585/gep.v12i1.18632.

\section{Introdução}

Com o desenvolvimento da disciplina de gerenciamento de projetos houve, paralelamente, a criação de diversas metodologias para melhorar os resultados dos projetos. Embora se saiba que o gerenciamento de projetos existia muito antes de sua formalização enquanto disciplina, foi durante a Guerra Fria que houve um aumento do interesse sobre o tema, quando o Departamento de Defesa dos Estados Unidos passou a investir em técnicas e ferramentas para acelerar os projetos militares (Valle, Soares, Finocchio, \& Silva, 2010).

Nesse período, surgem instituições dedicadas ao tema como a International Project Management Association (IPMA) em 1965, na Suíça; o Project Management Institute (PMI) em 1969, nos Estados Unidos (PMI, 2018); e, em 1989, na Grã-Bretanha, o

\section{Projects IN Controlled Environments}

(PRINCE) (Axelos, 2018). Embora com abordagens diferentes, todas as organizações citadas têm o intuito de disseminar as melhores práticas e, até mesmo, de criar padrões para o gerenciamento de projetos de qualquer natureza. Elas deram grande impulso à disciplina de gerenciamento de projetos e, a partir dos anos 90, seus métodos passaram a ser empregados por um grande número de empresas privadas e públicas. Percebeu-se um movimento nas organizações em direção ao gerenciamento estratégico de projetos (Shenhar, 2001; Valeriano, 2001). Deram forma, assim, ao denominado gerenciamento tradicional de projetos, cuja ênfase é o planejamento e controle com vistas ao melhor desempenho do projeto em termos de custos previstos e prazos pré-determinados

Encontra-se na abordagem tradicional a fundação do gerenciamento de projetos atual. 
Os métodos que usam essa abordagem são chamados de preditivos, pois se destacam pela sua extrema estruturação, sequenciamento e uso de controles e documentação sobre todas as decisões tomadas. Tornaram-se bastante difundidos pelo Guia Project Management Body of Kwnoledge (PMBOK), que descreve o conhecimento no âmbito da profissão de gerenciamento de projetos, incluindo práticas tradicionais comprovadas, amplamente aplicadas, bem como práticas inovadoras que surgem na profissão (Project Management Institute [PMI], 2017a).

Uma maneira de se analisar a forma como os projetos são gerenciados é por meio da forma como são planejados. O Agile Business Consortium (2014) apresenta uma divisão de planejamento com três classes, sendo que em cada uma há níveis diferentes de detalhamento do planejamento. Essas três classes são: a) Big Design Up Front [BDUF] (sem desenho completo à frente, em português) em que o projeto é todo planejado e detalhado antes de se iniciar as atividades. Requer que a totalidade ou, ao menos, grande parte dos requisitos já esteja determinada no início do projeto, ou seja, o escopo do projeto é sabido antecipadamente com baixas chances de mudança; b) Enough Design Up Front [EDUF] (desenho suficiente à frente, em português) em que vai se desenhando o projeto em ciclos. Aqui o projeto é planejado em fases, onde cada uma recebe um planejamento mais detalhado, em vez de planejar o projeto do início ao fim. Isso permite uma flexibilização no gerenciamento do projeto, proporcionando que mudanças sejam feitas ao longo do gerenciamento se assim for necessário; c) $N o$ Design Up Front [NDUF] (sem desenho a frente, em português) em que não há planejamento nenhum para o projeto. Esse modelo é o mais temido por organizações maiores e mais governadas devido ao seu maior risco. $\mathrm{O}$ projeto não é planejado à priori, pois os requisitos e escopo não são existentes, ou são apenas visionários.

O gerenciamento preditivo de projetos segue a primeira classe de tipos de planejamento, a BDUF, e tem sido questionado quanto à eficácia de sua aplicação na atualidade, devido ao fato de que os ambientes de negócios são cada vez mais dinâmicos e caracterizados pela dificuldade em prever o futuro, incertezas e grandes desafios. Nesse sentido, uma das abordagens metodológicas que vem ganhando destaque nas organizações é o gerenciamento ágil de projetos, cujo foco é a geração de valor para o cliente (Conforto \& Amaral, 2007; Wysocki, 2014).

Com princípios que remontam aos processos japoneses de manufatura lean anteriores à década de 1980, foi em 2001 que o Manifesto para o Desenvolvimento Ágil de Software foi lançado como contraponto aos métodos preditivos que, segundo os autores do manifesto, era muito concentrado em processos e documentos, não sendo direcionado à resolução dos problemas do projeto. O manifesto ágil baseou-se, então, nos seguintes pontos: indivíduos e iterações mais 
que processos e ferramentas; software em funcionamento mais que documentação abrangente; colaboração com o cliente mais que negociação de contratos; responder a mudanças mais que seguir um plano (Beck et al., 2001; Hollingsworth, 2011; Sauer, 2017).

Segundo os autores do manifesto ágil, a maior prioridade do gerente de projetos deve ser a satisfação do cliente por meio de um processo contínuo e adiantado de entregas com valor agregado. As mudanças de requisitos são bem-vindas e os gerentes devem aproveitá-las para gerar vantagem competitiva para o cliente (Beck et al., 2001). Dessa forma, a abordagem ágil segue o modelo Enough Design Up Front [EDUF], em que a equipe reflete, em ciclos regulares, sobre como tornar mais eficazes a própria equipe e o produto em desenvolvimento e, então, vai fazendo um refinamento contínuo.

Vários métodos ágeis ou estruturas de trabalho emergiram a partir do Manifesto Ágil, como por exemplo, o framework Scrum que propõe um ciclo curto para os projetos, em que o planejamento não é todo determinado no início do projeto, mas sim construído de forma iterativa, uma vez que se faz entregas parciais que são submetidas ao usuário para sua aprovação. Desta forma, trabalha-se de forma mais ágil no projeto, uma vez se permite correções de maneira mais rápida ao longo do ciclo do projeto (Schwaber, K. \& Sutherland, J, 2017).

O Lean Project Management também pode ser considerado uma metodologia ágil de gerenciamento de projetos, mas está mais focado em reduzir o desperdício no projeto e baseado no método de gerenciamento da corrente crítica (Critical Path Method [CPM]) desenvolvido na década de 1950 (Leach, 2005). O Dynamic System Development Method [DSDM] surgiu em 1994, com foco em garantir a qualidade das entregas. Esta metodologia surgiu para tentar resolver os problemas vistos na aplicação dos métodos preditivos, tais como taxas de sucesso baixas por conta das entregas atrasadas e, por vezes, desnecessárias (Agile Business Consortium, 2014). O XP [Xtreme Programming] surgiu com o intuito de resolver problemas no desenvolvimento de software ocasionados pelos longos ciclos de desenvolvimento (Beck et al, 1999). Nessa metodologia, o teste do software deve ser feito de forma rápida e cabe ao usuário definir a prioridade das entregas.

Nota-se, porém, que a adoção dos métodos ágeis tem sido feita sem uma reflexão mais profunda sobre sua adequabilidade aos diferentes tipos de projetos. Com o marco do Manifesto Ágil, vários métodos ágeis de gerenciamento de projetos passaram a surgir e os gestores de empresas começaram a considerar que todos os projetos devem ser executados de forma ágil, talvez influenciados por um dos princípios subjacentes do Lean Project Management, de que qualquer projeto que valha a pena ser feito vale a pena ser feito rápido (Leach, 2005)

Ao final dos anos 90 e início dos anos 2000, eclodiu a discussão sobre o fato de que a 
utilização de um método único, seja ele preditivo ou ágil, não seria, necessariamente, aplicável a todos os projetos. Essa corrente passou a adotar abordagens contingenciais e adaptativas para gerenciamento de projetos. Ou seja, dependendo da contingência, haveria métodos que se adaptariam melhor à especificidade de cada projeto. Nesse sentido, há autores como Shenhar e Dvir (2010) que propõem uma abordagem contingencial para o gerenciamento de projetos em que cada projeto apresenta características e complexidades diferentes e, assim sendo, devem ser geridos de forma diferenciada, utilizando-se de diferentes técnicas de acordo com a situação. Entende-se que o gerenciamento ágil, assim como o gerenciamento preditivo, tem suas aplicações específicas (Conforto \& Amaral, 2008; Highsmith, 2012; Shenhar, 2001).

Shenhar (2001) avalia que os projetos não devem ser geridos pela máxima do "um tamanho serve para todos" (one size fits all) e propõe que os projetos sejam geridos de forma contingencial, baseado em duas características: (a) Incerteza tecnológica e (b) Complexidade do sistema. Appelo (2011) justifica que os gestores devem gerir suas equipes de acordo com o desafio, de forma que uma equipe que trabalha em um ambiente estável deve ter tratamento diferente da equipe em um ambiente mais volátil, sendo que os gestores devem evitar o ambiente caótico, pois este se tornaria não gerenciável.

Kerzner (2013) define a complexidade em função do número de interações requeridas entre unidades funcionais para que o projeto seja executado. Quanto maior a necessidade de interações, maior a complexidade do projeto. A localização das unidades funcionais também é outro ponto considerado pelo autor. O projeto será mais complexo quando as unidades funcionais forem geograficamente distribuídas, seja por questões logísticas e/ou culturais. Por fim, quanto maiores forem o escopo, o custo e o prazo do projeto, também maior será a complexidade, dada a maior probabilidade de ocorrência de mudanças ao longo do projeto.

Os métodos preditivos seriam mais apropriados para projetos com objetivos e requisitos iniciais claros, com baixo nível de incerteza. Espera-se que tais projetos tenham uma taxa de mudança de requisitos muito baixa e que não seja necessário envolver fortemente os usuários finais no projeto. Outra recomendação do uso dos métodos preditivos seria em projetos de alta criticidade sistêmica, em que qualquer falha poderia ter consequências graves para o sistema como um todo. Nessas situações, a ênfase estaria na elaboração inicial de um plano de projeto que teria uma sequência previsível e linear com o objetivo de otimizar as atividades do projeto e buscar eficiência em sua execução. Projetos típicos dessa abordagem seriam os de rotina operacional, de construção ou engenharia (Kerzner, 2013; Conforto \& Amaral, 2008; Highsmith, 2012; Papadakis \& Tsironis, 2020; Shenhar, Milosevic, Dvir, \& Thamhain, 2007; Spundak, 2014; Wysocki, 2014). 
Quando se tratam de projetos criativos e inovadores, tais como projetos de pesquisa, de desenvolvimento de novos produtos ou mesmo de melhoria de processos, a abordagem ágil de gerenciamento de projetos seria a mais adequada. Todos esses projetos são caracterizados por alto nível de incerteza, objetivos de projeto pouco claros ou solicitações incompletas e imprevisíveis que podem alterar significativamente o curso do projeto. Em função dessas características, são organizados de forma iterativa, não linear, com frequentes modificações e atualizações do plano do projeto e requer colaboração próxima e frequente com o usuário final durante $o$ projeto (Conforto \& Amaral, 2008; Highsmith, 2012; Shenhar et al, 2007; Spundak, 2014; Wysocki, 2014).

Zasa e Pellizzoni (2021) discorrem que as organizações não pertencentes ao contexto da indústria de software, berço natural da abordagem ágil, têm, provavelmente, um gerenciamento de projetos mais tradicional e consolidado, com práticas que dificilmente serão abandonadas por completo. As empresas que optam por adotar métodos ágeis devem encontrar maneiras de fazer com que as diferentes práticas de gerenciamento de projetos possam coexistir de forma harmônica.

Os modelos híbridos têm surgido em resposta à necessidade de se fazer o melhor uso possível das diferentes práticas. Ao analisar a utilização do método stage-gate em conjunto com métodos ágeis, o chamado agilestage-gate, Cooper e Sommer (2020) apontam desafios que a empresa pode enfrentar quando da integração de práticas heterogêneas. Um deles é relacionado ao fato de que, como na abordagem ágil os projetos são ambíguos, em constante evolução e iterativos, torna-se mais difícil avaliar o valor econômico e o progresso dos projetos ao longo do tempo, aspecto que é central na metodologia stage-gate. Por outro lado, os autores entendem que a adoção da abordagem híbrida do agile-stage-gate tem possibilitado aumentos significativos na velocidade e produtividade de Pesquisa e Desenvolvimento [P\&D] em empresas do setor de manufatura que a adotaram.

O presente estudo ampara-se na abordagem contingencial da gestão de projetos ao entender que o gerente de projetos não precisa estar preso a uma única abordagem metodológica, podendo utilizar-se de um ou mais métodos de acordo com a necessidade do projeto. Há uma corrente de autores que defendem o uso de métodos híbridos que associam os modelos preditivos de gestão de projetos com as boas práticas do modelo ágil de gestão de projetos. Essa associação de boas práticas visa obter melhores resultados, conciliando agilidade e flexibilidade com previsibilidade, tendo em vista que há projetos que apresentam desafios que nem os métodos ágeis nem as abordagens estruturadas tradicionais podem enfrentar de forma eficaz por si só. Essa abordagem é conhecida como adaptativa (Batra, D., Xia, W., Vandermeer, D., \& Dutta, 2010; Cooper \& Sommer, 2020; Spundak, 2014; Zasa \& Pellizzoni, 2021). 
Feitas todas essas considerações, o foco do presente estudo é o gerenciamento de projetos sob a ótica da abordagem adaptativa, que se utiliza de métodos híbridos, entendendo-a como um continuum entre os métodos preditivos e ágeis. Mais especificamente, considerando que os projetos podem se utilizar de diferentes métodos e técnicas adequadas a contextos específicos, interessa saber quais artefatos das abordagens preditiva e ágil são utilizados.

Cabe apresentar a definição de artefato no contexto deste estudo. De acordo com o PMBOK, os artefatos podem ser processos de gerenciamento de projetos, entradas, ferramentas, técnicas e saídas (PMI, 2017a). Para efeito deste estudo, artefatos são tratados como objetos tangíveis gerados pelo gerenciamento do projeto, especificamente relacionados ao escopo do projeto. Tais artefatos podem ser objetos tangíveis ou apenas existirem e estarem armazenados em meio eletrônico como, por exemplo, em sistemas de gerenciamento de projetos.

Outro aspecto que embasa o estudo é a complexidade do projeto, ou seja, a existência de um grande número de variáveis a serem administradas (Maximiano, 2007; Yugue \& Maximiano, 2013), por se entender que essa é uma variável dos projetos com impactos diretos nas decisões sobre o gerenciamento do projeto, incluindo as práticas a serem utilizadas (Geraldi, Maylor \& Williams, 2011).

Vários autores publicaram diferentes maneiras de se medir a complexidade dos projetos (Alba et al., 2016; Dao, Kermanshachi, Shane, Anderson, \& Hare, 2016; PMI, 2014; Poveda-Bautista, DiegoMas, \& Leon-Medina, 2018; Souza Pinto, Novaski, Anholon, \& Besteiro, 2014; Vidal, Marle, \& Bocquet, 2011). Para esse estudo foi utilizada a escala da Global Alliance for the Project Professions [GAPPS], que caracteriza os projetos em três níveis de complexidade e assim determina a competência necessária do gerente de projetos. A escala será apresentada no item dedicado aos procedimentos metodológicos da pesquisa (GAPPS, 2007).

O estudo está delimitado à área de gerenciamento do escopo do projeto, considerada fundamental em quaisquer abordagens metodológicas, pois, qualquer que seja o contexto, há que se garantir que os requisitos do projeto atendam às expectativas dos clientes. Portanto, a questão de pesquisa que norteou o estudo, no contexto da abordagem adaptativa de gerenciamento de projetos foi: "quais artefatos os gestores de projeto e suas organizações utilizam na gestão do escopo do projeto, de acordo com a complexidade do projeto"?

Logo, o objetivo da pesquisa foi mapear quais os tipos de artefatos estão sendo utilizados pelos gerentes de projetos para suportar o gerenciamento de escopo dos projetos, bem como verificar se os gerentes de projetos e suas organizações adotam uma abordagem adaptativa de gerenciamento de seus projetos. Para isso foi consolidado, com base na revisão da literatura, um conjunto de 
artefatos tradicionais e ágeis para gerenciamento de escopo do projeto. Em seguida, foram verificados, por meio de levantamento, quais os artefatos mais utilizados pelos gerentes de projetos e os motivos que embasam suas escolhas.

É importante destacar que o presente estudo adota o termo "escopo", mais formalmente utilizado nas metodologias tradicionais de gestão de projetos, para definir, de uma forma geral, o que também é chamado de "requisitos" ou "Produto Viável Mínimo" nas metodologias ágeis, de forma que o termo “escopo" pode ser entendido como o entregável do projeto ou da iteração.

O estudo oferece uma contribuição acadêmica quanto à consolidação dos artefatos disponíveis para o gerenciamento de escopo de um projeto, tanto na corrente tradicional quanto na corrente ágil. Também contribui no levantamento dos artefatos que estão realmente em uso, no sentido de melhor se entender como é a feita a escolha dos artefatos, independentemente de abordagens metodológicas únicas. Espera-se que os resultados possam contribuir com a prática das empresas, auxiliando-as a decidir sobre o uso de técnicas e artefatos para gerenciamento de escopo existentes em ambas as abordagens, evitando utilizar indiscriminadamente as metodologias ágeis ou se manter enraizados nos controles e planos das metodologias tradicionais. Dessa forma, as escolhas metodológicas poderão ser feitas tendo em vista os objetivos do projeto e não as preferências dos gestores.

\section{Procedimentos metodológicos}

A presente pesquisa tem natureza aplicada e utiliza-se de uma abordagem quantitativa. No tocante aos objetivos, um estudo pode apresentar mais de um alcance, sendo que a parte exploratória é destinada a preparar o terreno para a parte descritiva, cuja meta é descrever fenômenos e situações (Sampieri, Collado, \& Lucio, 2013). A pesquisa ora apresentada tem propósitos exploratórios e descritivos sendo que, inicialmente, explorou-se o quanto as empresas utilizam a gestão adaptativa de projetos para depois descrever esse fenômeno por meio da análise da utilização dos artefatos pelos gestores de projetos.

A pesquisa foi feita em três etapas distintas. Inicialmente, foi feita uma pesquisa bibliográfica para identificação e consolidação dos artefatos utilizados em gestão de projetos no âmbito tradicional e ágil, de acordo com a literatura disponível sobre o tema. $\mathrm{Na}$ sequência, definiram-se os artefatos específicos à área de gerenciamento de escopo.

$\mathrm{Na}$ segunda etapa, ainda mediante pesquisa bibliográfica, buscou-se definir escalas de medição da complexidade do projeto, tendo em vista que a pesquisa não visa discutir a complexidade como tema principal, mas sim usar uma escala para mensurar a complexidade dos projetos estudados, de forma a permitir relacioná-los e compará-los. 
De posse dos resultados das etapas $1 \mathrm{e}$ 2, procedeu-se terceira etapa, em que foi aplicado o método quantitativo de levantamento ou survey. Segundo Babbie (1999), a adoção desse tipo de pesquisa permite ao pesquisador documentar processos causais com vasto número de variáveis, estando em situação bastante favorável para uma análise da importância de cada uma delas, podendo quantificá-las e processá-las em computador. Por outro lado, o pesquisador não possui controle sobre os eventos comportamentais e também não intervém na realização das respostas, seguindo uma sistemática pré-determinada na qual poderão ser utilizadas análises estatísticas para a avaliação dos dados.

Foi desenvolvido um questionário com base na bibliografia e em discussões com especialistas em gerenciamento de projetos. Inicialmente, foi feito um pré-teste com três gerentes de projetos, público-alvo da pesquisa, com o intuito de avaliar o questionário quanto a sua objetividade, clareza e facilidade para respondê-lo (Forza, 2002). O questionário foi composto por 20 questões e utilizou a escala Likert de 5 pontos, exceto para as questões sobre complexidade dos projetos, que seguiram o modelo proposto pela Global Alliance for the Project Professions (GAPPS, 2007), e foram apenas traduzidas do original em inglês para o português pelos autores. Desta forma, após o levantamento dos artefatos e definição da escala de complexidade, criouse o questionário, que após os ajustes necessários identificados no pré-teste, foi aplicado aos respondentes por meio de links disponibilizados em mídias sociais como LinkedIn, Facebook e WhatsApp. Também foi enviado um link com questionário para alunos e ex-alunos dos cursos de gestão de projetos do Programa de Gestão de Projetos da Fundação Instituto de Administração (GPRO/FIA). Além disso, foi disponibilizado um $Q R$ Code para duas turmas correntes de cursos relacionados a gerenciamento de projetos. Por fim, o questionário previu que o respondente pudesse indicar outra pessoa para respondê-lo, de forma a se utilizar o método "bola de neve" para alcançar um maior volume de respostas. Observa-se, portanto, que foi utilizada uma amostra não probabilística.

Para que as respostas aos questionários fossem consideradas válidas para análise, elegeram-se os seguintes critérios:

- Ser respondido por um gerente de projetos ou dono de produto (product owner);

- Ter respostas sobre a frequência de utilização para todos os artefatos elencados;

- Ter respostas para as três perguntas sobre a liberdade de escolha permitida pela empresa;

- Ter respostas para todas as questões relativas à complexidade do projeto.

Desta forma, a pesquisa atingiu um total de 129 respondentes, sendo que 41 respostas foram consideradas válidas de acordo com os critérios anteriormente especificados. 
Para a análise dos dados, adotou-se, inicialmente, a estatística descritiva, acrescida da técnica multivariada de análise de agrupamentos para se consolidar os artefatos em grupos de utilização de acordo com a complexidade do projeto. Utilizando-se o software Minitab, foi realizada uma análise de agrupamento usando a medida euclidiana quadrada, que é a distância recomendada para a utilização em conjunto com o método Ward de agrupamento (Hair, Anderson, Tatham, \& Black (2005), sobre os valores de complexidade para as respostas "Sempre" e “Quase Sempre”. O método Ward foi escolhido por utilizar a soma interna de todas as variáveis do agrupamento para determinar o próximo agrupamento. Também se levou em consideração o fato deste método tender a gerar agrupamentos com o mesmo número de observações, ou seja, a mesma quantidade de artefatos por grupo.

Para efeito de análise, posto que o objetivo da pesquisa foi avaliar a intensidade de uso dos artefatos para uma dada complexidade, as respostas foram agregadas da seguinte forma: o intervalo compreendido entre "quase sempre" e "sempre" foi tratado como "utilizado" e o intervalo entre "nunca" e "quase nunca" foi tratado como "não utilizado".

\subsection{Etapa 1 - Identificação e consolidação dos artefatos}

O levantamento teórico realizado constatou a grande extensão de artefatos utilizados no gerenciamento de projetos, em especial no modelo preditivo. Em função da delimitação da pesquisa, restringiu-se aos artefatos relacionados ao gerenciamento do escopo do projeto, visto que essa é uma das áreas de conhecimento do PMBOK (PMI, 2017a) que permeia todos valores do manifesto ágil como apresentado no quadro 1.

Quadro 1 - Correlação entre métodos ágeis e adaptativos na área de gerenciamento de escopo do projeto

\begin{tabular}{|l|l|}
\hline \multicolumn{1}{|c|}{ Manifesto ágil } & \multicolumn{1}{c|}{$\begin{array}{c}\text { Áreas de conhecimento PMBOK } \\
\text { (Gerenciamento de escopo) }\end{array}$} \\
\hline $\begin{array}{l}\text { Indivíduos e interações mais que processos e } \\
\text { ferramentas }\end{array}$ & $\begin{array}{l}\text { A equipe do projeto atua na definição do escopo } \\
\text { do projeto }\end{array}$ \\
\hline $\begin{array}{l}\text { Software em funcionamento mais que } \\
\text { documentação abrangente }\end{array}$ & $\begin{array}{l}\text { O escopo do projeto está constantemente sendo } \\
\text { entregue }\end{array}$ \\
\hline $\begin{array}{l}\text { Colaboração com o cliente mais que } \\
\text { negociação de contratos }\end{array}$ & $\begin{array}{l}\text { Cliente e equipe do projeto interagem } \\
\text { constantemente definindo o escopo }\end{array}$ \\
\hline $\begin{array}{l}\text { Responder a mudanças mais que seguir um } \\
\text { plano }\end{array}$ & O escopo é modificado sempre que necessário \\
\hline
\end{tabular}

Fonte: Elaborado pelos autores, 2020.

O quadro 1 permite verificar que, no que tange ao escopo do projeto, embora com linguagens diferentes, há uma similaridade de propósitos entre os métodos ágeis e preditivos. É interessante verificar que na metodologia preditiva, base do PMBOK (PMI, 2017a), o 
escopo, em que pese ser definido no início do projeto, permite mudanças e interações ao longo do projeto, contrariando a visão de que o método preditivo é muito engessado.

Para o levantamento dos artefatos das metodologias preditivas, utilizou-se o Guia PMBOK (PMI, 2017a) como referência, com o intuito de manter um padrão de análise e visto que esse guia é, por si só, uma compilação das melhores práticas de gerenciamento preditivo de projetos. Para definição dos artefatos da abordagem ágil, foram utilizados os métodos
SCRUM, XP, LEAN e DSDM, no que tange ao gerenciamento do escopo.

O quadro 2 apresenta os artefatos da metodologia preditiva e o quadro 3 apresenta os relacionados aos métodos ágeis. O quadro 4 apresenta os artefatos consolidados, tanto na abordagem preditiva como ágil. Na primeira coluna estão os artefatos e, na segunda coluna, estão associadas as variáveis relacionadas aos métodos preditivo e ágil a serem utilizadas na análise de dados.

Quadro 2 - Artefatos preditivos relacionados ao escopo de acordo com o ciclo de vida do projeto (PMBOK)

\begin{tabular}{|c|c|c|}
\hline $\begin{array}{l}\text { Etapa do Ciclo de } \\
\text { Vida do Projeto }\end{array}$ & Artefatos & Definição \\
\hline \multirow{4}{*}{ Início do projeto } & $\begin{array}{l}\text { Plano de } \\
\text { gerenciamento dos } \\
\text { requisitos }\end{array}$ & $\begin{array}{l}\text { Plano que descreve como os requisitos do projeto e produto do } \\
\text { projeto serão analisados, documentados e gerenciados. Faz parte } \\
\text { do plano de gerenciamento do projeto. }\end{array}$ \\
\hline & $\begin{array}{l}\text { Registro das partes } \\
\text { interessadas }\end{array}$ & $\begin{array}{l}\text { Elaboração do documento contendo as características das partes } \\
\text { interessadas do projeto, sua avaliação e classificação de acordo } \\
\text { com o definido no plano de engajamento das partes } \\
\text { interessadas. }\end{array}$ \\
\hline & $\begin{array}{l}\text { Registros de } \\
\text { premissas }\end{array}$ & $\begin{array}{l}\text { Elaboração de documento para registrar as premissas e } \\
\text { restrições ao longo do projeto. Premissas são aquelas } \\
\text { informações que são assumidas como verdadeiras, pois são } \\
\text { desconhecidas no momento de iniciação do projeto. }\end{array}$ \\
\hline & $\begin{array}{l}\text { Solicitação de } \\
\text { mudança }\end{array}$ & $\begin{array}{l}\text { Elaboração de documento para solicitação formal realizada para } \\
\text { mudar algum template, entrega ou linha de base do projeto. } \\
\text { Estas solicitações podem ser aprovadas ou rejeitadas. }\end{array}$ \\
\hline \multirow{7}{*}{$\begin{array}{l}\text { Planejamento e } \\
\text { organização do } \\
\text { projeto. }\end{array}$} & $\begin{array}{l}\text { Documentação dos } \\
\text { requisitos }\end{array}$ & $\begin{array}{l}\text { Documento contendo os requisitos do produto e do projeto nos } \\
\text { diferentes aspectos, como requisitos do negócio, expectativas } \\
\text { das partes interessadas, funcionalidades do produto etc. }\end{array}$ \\
\hline & $\begin{array}{l}\text { Especificação do } \\
\text { escopo do projeto }\end{array}$ & $\begin{array}{l}\text { Documento que descreve todo o escopo do projeto e do produto, } \\
\text { detalhando as entregas do projeto, ou seja, descreve tudo o que } \\
\text { será feito no projeto e como será aceito. Pode também conter } \\
\text { explicitamente o que não será feito no projeto. }\end{array}$ \\
\hline & $\begin{array}{l}\text { Linha de base do } \\
\text { cronograma }\end{array}$ & Documento aprovado contendo o cronograma do projeto. \\
\hline & $\begin{array}{l}\text { Linha de base do } \\
\text { escopo. }\end{array}$ & $\begin{array}{l}\text { Documento aprovado contendo a declaração do escopo do } \\
\text { projeto, a estrutura analítica e seu dicionário. }\end{array}$ \\
\hline & $\begin{array}{l}\text { Linha de base dos } \\
\text { custos. }\end{array}$ & $\begin{array}{l}\text { Documento aprovado contendo os custos do projeto, excluindo- } \\
\text { se a reserva gerencial ao longo do tempo. }\end{array}$ \\
\hline & $\begin{array}{l}\text { Matriz de } \\
\text { rastreabilidade dos } \\
\text { requisitos }\end{array}$ & Tabela que liga os requisitos com as entregas que as satisfazem. \\
\hline & $\begin{array}{l}\text { Plano de } \\
\text { gerenciamento do } \\
\text { escopo }\end{array}$ & $\begin{array}{l}\text { Plano que descreve como o escopo será definido, desenvolvido, } \\
\text { monitorado, controlado e validado. Faz parte do plano de } \\
\text { gerenciamento do projeto. }\end{array}$ \\
\hline
\end{tabular}


Rabetti, D., \& Rodrigues I. (2021, Ed. Esp. jan./abr.). Gestão adaptativa de projetos: um levantamento dos artefatos mais utilizados para gerenciar o escopo do projeto

\begin{tabular}{|c|c|c|}
\hline $\begin{array}{l}\text { Etapa do Ciclo de } \\
\text { Vida do Projeto }\end{array}$ & Artefatos & Definição \\
\hline & $\begin{array}{l}\text { Plano de } \\
\text { gerenciamento dos } \\
\text { requisitos. }\end{array}$ & $\begin{array}{l}\text { Plano que descreve como os requisitos do projeto e produto do } \\
\text { projeto serão analisados, documentados e gerenciados. Faz parte } \\
\text { do plano de gerenciamento do projeto. }\end{array}$ \\
\hline \multirow{3}{*}{$\begin{array}{l}\text { Execução e } \\
\text { acompanhamento do } \\
\text { projeto. }\end{array}$} & Entregas aceitas. & $\begin{array}{l}\text { Documento de formalização perante o cliente ou patrocinador } \\
\text { que as entregas estão dentro dos critérios de aceitação } \\
\text { estabelecidos. }\end{array}$ \\
\hline & $\begin{array}{l}\text { Informações sobre } \\
\text { desempenho do } \\
\text { trabalho. }\end{array}$ & $\begin{array}{l}\text { Documento com as medições e observações realizadas durante a } \\
\text { execução da(s) atividade(s) do projeto. }\end{array}$ \\
\hline & $\begin{array}{l}\text { Linha de base da } \\
\text { medição do } \\
\text { desempenho. }\end{array}$ & $\begin{array}{l}\text { Documento aprovado contendo o desempenho do projeto, } \\
\text { integrando escopo-cronograma-custo. }\end{array}$ \\
\hline $\begin{array}{l}\text { Encerramento do } \\
\text { projeto. }\end{array}$ & $\begin{array}{l}\text { Registro de lições } \\
\text { aprendidas. }\end{array}$ & $\begin{array}{l}\text { Registro contendo documentos, vídeos, fotos, gravações do } \\
\text { aprendizado, incluindo dificuldades, problemas, riscos e } \\
\text { oportunidades adquiridos ao longo do projeto, de tal forma que } \\
\text { possa ser pesquisado e utilizado pelos membros do time e em } \\
\text { outros projetos. }\end{array}$ \\
\hline
\end{tabular}

Fonte: Elaborado pelos autores, 2020.

Quadro 3 - Artefatos das metodologias ágeis de gerenciamento de projetos

\begin{tabular}{|c|c|c|}
\hline $\begin{array}{l}\text { Metodologia de } \\
\text { gerenciamento ágil }\end{array}$ & Artefatos & Definição \\
\hline \multirow{3}{*}{ SCRUM } & Backlog do Produto & $\begin{array}{l}\text { Lista contendo, de forma ordenada, tudo o que deve ser } \\
\text { necessário no produto, sendo desta forma a lista única de } \\
\text { requisitos do produto. Ela é atualizada constantemente } \\
\text { conforme novas informações vão sendo descobertas ou } \\
\text { refinadas. Ela contém a estimativa de esforço necessário para } \\
\text { completamente de cada um de seus itens. }\end{array}$ \\
\hline & $\begin{array}{l}\text { Backlog da } \\
\text { Sprint/timebox }\end{array}$ & $\begin{array}{l}\text { Lista contendo os requisitos do produto a serem trabalhados no } \\
\text { sprint sendo, portanto, um subconjunto do backlog do produto, } \\
\text { contendo os itens selecionados desta. }\end{array}$ \\
\hline & $\begin{array}{l}\text { Incremento do } \\
\text { produto }\end{array}$ & $\begin{array}{l}\text { Soma dos resultados da sprint atual com as anteriores, estando } \\
\text { em condição de uso, ou "pronto", ou seja, é o "resultado" do } \\
\text { projeto até o momento. }\end{array}$ \\
\hline \multirow{3}{*}{$\mathrm{XP}$} & Estórias. & $\begin{array}{l}\text { Descrições simples do ponto de vista do usuário de } \\
\text { implementações necessárias no software. }\end{array}$ \\
\hline & Metáfora & $\begin{array}{l}\text { Criada para que todos tenham uma visão geral do sistema, } \\
\text { permitindo que todos possam explicar a função do sistema de } \\
\text { forma que programadores, clientes, gerentes entre outros } \\
\text { possam compreender os elementos básicos do sistema. }\end{array}$ \\
\hline & Quadro de tarefas & Nome dado ao quadro kanban no XP. \\
\hline \multirow{2}{*}{$\begin{array}{l}\text { LEAN PROJECT } \\
\text { MANAGEMENT }\end{array}$} & $\begin{array}{l}\text { Característica } \\
\text { comercializável } \\
\text { mínima }\end{array}$ & $\begin{array}{l}\text { É a menor funcionalidade com valor para o cliente que o time } \\
\text { do projeto pode entregar. }\end{array}$ \\
\hline & $\begin{array}{l}\text { Gráfico de trabalho } \\
\text { em progresso (WIP - } \\
\text { Work In Progress) }\end{array}$ & $\begin{array}{l}\text { Gráfico que representa a evolução dos entregáveis de um } \\
\text { projeto ao longo do processo. Também chamado de quadro } \\
\text { Kanban. }\end{array}$ \\
\hline DSDM & Business case. & $\begin{array}{l}\text { Documento que captura os fatores críticos de sucesso do } \\
\text { projeto, fatores esses que justificam a existência do projeto. No } \\
\text { DSDM esse documento é atualizado a cada incremento do } \\
\text { produto ou ao final de fase para verificar se o projeto ainda se } \\
\text { mantem necessário. }\end{array}$ \\
\hline
\end{tabular}


Rabetti, D., \& Rodrigues I. (2021, Ed. Esp. jan./abr.). Gestão adaptativa de projetos: um levantamento dos artefatos mais utilizados para gerenciar o escopo do projeto

\begin{tabular}{|c|c|c|}
\hline $\begin{array}{l}\text { Metodologia de } \\
\text { gerenciamento ágil }\end{array}$ & Artefatos & Definição \\
\hline & $\begin{array}{l}\text { Definição da } \\
\text { arquitetura da solução. }\end{array}$ & $\begin{array}{l}\text { Contém o desenho em alto nível da solução, conciliando } \\
\text { aspectos técnicos e do negócio. }\end{array}$ \\
\hline & Estórias. & $\begin{array}{l}\text { Descrições simples do ponto de vista do usuário de } \\
\text { implementações necessárias no software. }\end{array}$ \\
\hline & $\begin{array}{l}\text { Lista de } \\
\text { requerimentos } \\
\text { priorizada. }\end{array}$ & $\begin{array}{l}\text { Lista de requerimentos priorizada: lista contendo a descrição, } \\
\text { em alto nível, dos requerimentos do projeto, de forma } \\
\text { priorizada. Essa descrição vai evoluindo em termos de } \\
\text { detalhamento ao longo do projeto. }\end{array}$ \\
\hline & Quadro do time & Quadro do time: nome dado ao quadro kanban no DSDM. \\
\hline Compartilhados & Quadro Kanban & $\begin{array}{l}\text { Quadro contendo as tarefas a serem executadas, em execução e } \\
\text { completadas dentro da interação. }\end{array}$ \\
\hline
\end{tabular}

Fonte: Elaborado pelos autores, 2020.

Quadro 4 - Artefatos e Variáveis por método de gerenciamento

\begin{tabular}{|c|c|c|}
\hline \multirow[b]{2}{*}{ Artefatos } & \multicolumn{2}{|c|}{ Nome da variável } \\
\hline & $\begin{array}{c}\text { Método preditivo } \\
\text { (PMBOK) }\end{array}$ & Método ágil \\
\hline Backlog da timebox & & A1 \\
\hline Backlog do Produto & & $\mathrm{A} 2$ \\
\hline Business case & & A3 \\
\hline Característica comercializável mínima & & A4 \\
\hline Definição da arquitetura da solução & & A5 \\
\hline Documentação dos requisitos & $\mathrm{P} 1$ & \\
\hline Entregas Aceitas & $\mathrm{P} 2$ & \\
\hline Especificação do escopo do projeto & P3 & \\
\hline Estórias & & A6 \\
\hline Incremento do produto & & A7 \\
\hline Informações sobre desempenho do trabalho & $\mathrm{P} 4$ & \\
\hline Linha de base da medição do desempenho & P5 & \\
\hline Linha de base do cronograma & P6 & \\
\hline Linha de base do escopo & P7 & \\
\hline Linha de base dos custos & P8 & \\
\hline Lista de requerimentos priorizada & & A8 \\
\hline Matriz de rastreabilidade dos requisitos & $\mathrm{P9}$ & \\
\hline Metáfora & & A9 \\
\hline Plano de gerenciamento do escopo & $\mathrm{P} 10$ & \\
\hline Plano de gerenciamento dos requisitos & P11 & \\
\hline Quadro Kanban/WIP/time & & A10 \\
\hline Registro das lições aprendidas & P12 & \\
\hline Registro das partes interessadas & P13 & \\
\hline Registro de premissas & $\mathrm{P} 14$ & \\
\hline Solicitação de mudança & $\mathrm{P} 15$ & \\
\hline
\end{tabular}

Fonte: Elaborado pelos autores, 2020.

\subsection{Etapa 2 - Escala de Complexidade}

Para a medição da complexidade do projeto, foi adotada uma escala proposta pela
GAPPS, uma aliança sem fins lucrativos, dirigida por voluntários, que fornece uma fonte confiável para comparação de padrões e 
qualificações baseados em projetos. Este modelo de escala de complexidade foi selecionado em função de ser curto, com apenas 7 atributos, ao contrário de outros modelos que foram analisados. Esse critério teve como base a elaboração de um questionário mais enxuto a fim de aumentar a probabilidade de obtenção das respostas. Outro ponto relevante na escolha foi $\mathrm{o}$ fato de $\mathrm{o}$ modelo estar bem descrito no "A Framework for Performance Based Competency Standards for Global Level 1 and 2 Project Managers" de 2007 da GAPPS. O quadro 5 apresenta as variáveis utilizadas na análise dos resultados para a escala de complexidade, de forma que o valor da complexidade do projeto foi obtido pela soma dos valores dos sete fatores que a compõem, ou seja, $\mathrm{CT}=\mathrm{C} 1+\mathrm{C} 2+\mathrm{C} 3+\mathrm{C} 4+$ $\mathrm{C} 5+\mathrm{C} 6+\mathrm{C} 7$.

Quadro 5 - Variáveis do fator de complexidade do projeto

\begin{tabular}{|r|l|l|}
\hline \multicolumn{2}{|l|}{ Fator de complexidade do gerenciamento do projeto } & Variável \\
\hline 1) & Estabilidade geral do contexto do projeto & $\mathrm{C} 1$ \\
\hline 2) & $\begin{array}{l}\text { Número de disciplinas distintas, métodos ou abordagens envolvidas na } \\
\text { performace do projeto }\end{array}$ & $\mathrm{C} 2$ \\
\hline 3) & $\begin{array}{l}\text { Implicações da magnitude legal, social ou ambiental para performace do projeto } \\
\text { 4) }\end{array} \begin{array}{l}\text { Impacto financeiro geral esperado (positivo ou negativo) para as partes } \\
\text { interessadas do projeto }\end{array}$ & $\mathrm{C} 4$ \\
\hline 5) & Importância estratégica do projeto para a organização ou organizações envolvidas & $\mathrm{C5}$ \\
\hline 6) & Coesão das partes interessadas em relação as características do produto do projeto & $\mathrm{C6}$ \\
\hline 7) & $\begin{array}{l}\text { Quantidade e a variedade de interfaces entre o projeto e outras entidades } \\
\text { organizacionais }\end{array}$ & $\mathrm{C} 7$ \\
\hline Complexidade do projeto & $\mathrm{CT}=\mathrm{C} 1+\mathrm{C} 2+\mathrm{C} 3+\mathrm{C} 4+\mathrm{C} 5+\mathrm{C} 6+\mathrm{C} 7$ \\
\hline
\end{tabular}

Fonte: Elaborado pelos autores com base em GAPPS (2007).

\section{Análise e discussão dos resultados}

A primeira análise realizada foi com relação ao grau de liberdade que as empresas oferecem aos seus gestores de projetos para a escolha dos artefatos. Assim, foram criadas três perguntas para avaliar como as empresas flexibilizam a utilização dos artefatos de gerenciamento de escopo pelos gestores do projeto. As perguntas e suas respectivas variáveis são apresentadas no quadro 6 .

Quadro 6 - Perguntas e variáveis para liberdade de uso de artefatos

\begin{tabular}{|l|l|}
\hline Pergunta & Variável \\
\hline $\begin{array}{l}\text { A empresa determina que os mesmos artefatos sejam } \\
\text { gerados para todos os projetos? }\end{array}$ & L1 \\
\hline $\begin{array}{l}\text { A empresa determina quais os artefatos serão gerados de } \\
\text { acordo com o projeto? }\end{array}$ & L2 \\
\hline $\begin{array}{l}\text { A empresa permite que o gestor do projeto selecione os } \\
\text { artefatos a serem gerados pelo projeto? }\end{array}$ & L3 \\
\hline
\end{tabular}

Fonte: Elaborado pelos autores, 2020. 
Silveira, T. B. J., \& Lemos, D. da C. (2021, Ed. Esp. jan./abr.). Colaboração com clientes e inovação aberta no desenvolvimento àgil de software: uma revisão sistemática de literatura

A figura 1 apresenta o percentual de cada resposta para cada uma das questões apresentadas no quadro 6. A primeira pergunta (L1) visou saber se a empresa trata todos os projetos da mesma forma. Pelas respostas obtidas, somando-se as respostas "sempre" e "quase sempre", verifica-se que, em quase $44 \%$ dos casos, as empresas gerenciam os projetos da mesma forma. Interessante ressaltar que $39 \%$ dos respondentes indicaram "ás vezes", o que parece indicar que uma possível abordagem adaptativa esteja ocorrendo nas empresas, confirmando achados de Kerzner (2013).

Figura 1 - Percentual de respostas sobre liberdade de escolha de artefatos

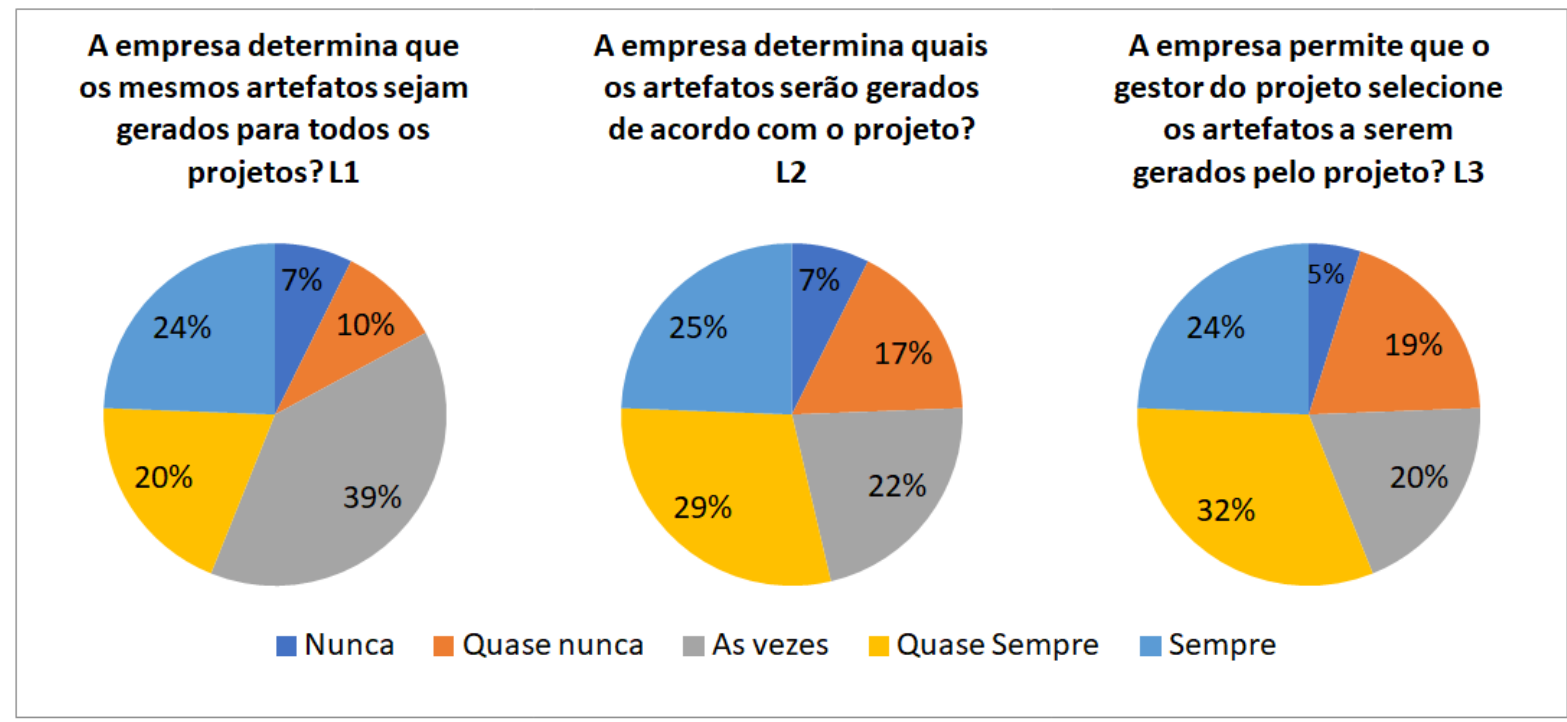

Fonte: Elaborado pelos autores, 2020.

Para a segunda questão (L2) cujo objetivo era identificar se as empresas definem os artefatos de gerenciamento de escopo de acordo a tipologia de projetos da empresa, observa-se que, praticamente, $54 \%$ dos respondentes indicam que isso ocorre "Sempre" ou "Quase sempre". Esse dado também corrobora o fato de que as empresas possam estar migrando para uma adoção contingencial de gestão de projetos, pois, apesar de indicarem quais os artefatos devem ser utilizados, estes artefatos podem variar de acordo com o tipo de projeto. Os resultados parecem corroborar com os autores que defendem que os projetos devem ser tipificados antes de se selecionar o modelo de gestão a ser utilizado (Shenhar, 2001; Wysocki, 2014).

Para a questão L3 observou-se que, aproximadamente, $56 \%$ dos respondentes indicaram a possibilidade de livre escolha dos artefatos, assinalando "Sempre" ou "Quase sempre" como resposta a essa questão. Desta forma, pode-se inferir que mais da metade das empresas estudadas já considera que o gestor do projeto deve ter abertura para determinar o que deve ser usado para a gestão do projeto, buscando dessa forma o sucesso do mesmo, 
não se limitando a um modelo específico, mas sim adaptando o que for necessário (PMI, 2017b, Shenhar, 2001; Shenhar \& Dvir, 2010; Wysocki, 2014).
Utilizando-se o coeficiente de correlação de Pearson (tabela 1), verifica-se que há uma correlação positiva entre as questões L1 e L2, e uma correlação negativa entre estas e a pergunta L3.

Tabela 1 - Correlação entre questões de liberdade de escolha de artefatos

\begin{tabular}{cccc}
\hline & L1 & L2 & L3 \\
\hline L1 & 1 & & \\
L2 & 0.772986 & 1 & \\
L3 & -0.49369 & -0.46076 & \\
\hline \multicolumn{4}{l}{ Fonte: Elaborado pelos autores, 2020. }
\end{tabular}

Sendo L1 e L2 centradas no aspecto de que as empresas determinam os artefatos a serem usados e que a L3 avalia a liberdade de escolha dos artefatos pelo gestor do projeto, percebe-se que as empresas ainda os determinam, pois se obteve altas taxas de respostas "Sempre" e "Quase sempre" nas questões L1 e L2. Porém, como há um percentual significativo de respostas "às vezes" para a questão L1 e de "sempre" e "quase sempre" para a questão L3, parece que há em curso um entendimento da importância de uma gestão mais flexível dos projetos tendo em vista seus objetivos (Kerzner, 2013; Shenhar \& Dvir, 2010; Wysocki, 2014).

Importante ressaltar, então, a importância de que as empresas entendam o gerenciamento de projetos como um processo não linear (Shenhar \& Dvir, 2010). Obviamente não se espera que as empresas deem "carta branca" para que o gerente projeto guie o projeto como quiser, mas sim que forneçam um framework flexível e treinem suas equipes para que possam se empoderar dessa flexibilidade para gerar melhores resultados (Wysocki, 2014). Os resultados devem estar conectados com os objetivos estratégicos da empresa e, portanto, devem ser geridos de uma forma contingencial (Shenhar et al., 2007; Senhar \& Dvir, 2010).

A segunda análise concentrou-se nos artefatos que, de fato, estão sendo utilizados pelos gestores de projetos, por escolha própria ou não. Para isso, calculou-se o percentual de cada resposta ("nunca", "quase nunca", "às vezes", "quase sempre" e "sempre"). Observase que entre os cinco artefatos mais utilizados - resposta "sempre" - todos são preditivos (indicados, na figura 2 pelo contorno verde) e entre os cinco menos utilizados - resposta "nunca" - quatro são ágeis (indicados pelo contorno vermelho). 
Figura 2 - Percentuais de utilização dos artefatos

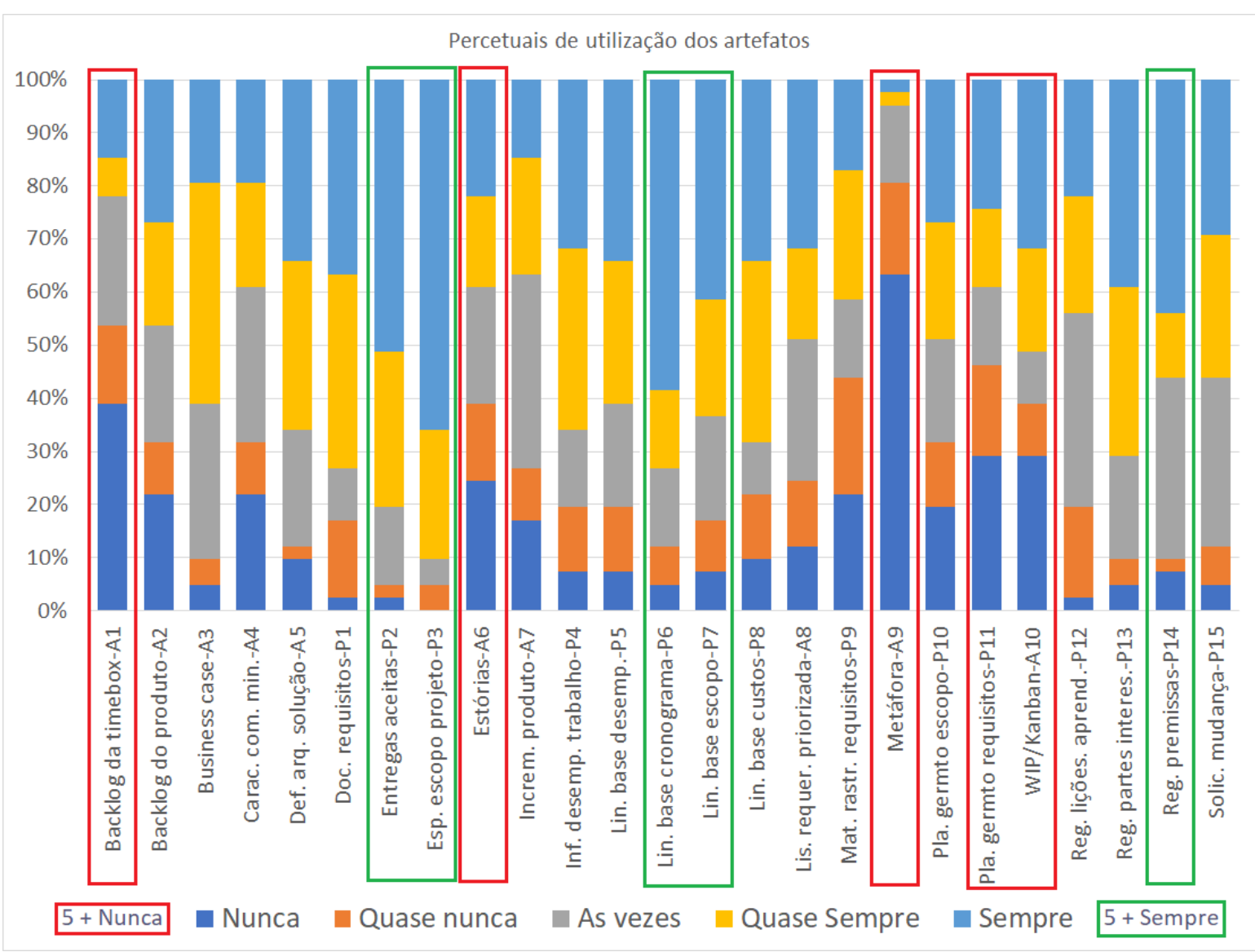

Fonte: Elaborado pelos autores, 2020.

Uma suposição que pode ser feita a partir dos resultados é que, embora esteja aumentando o grau de liberdade de escolha do gerente de projetos em relação aos artefatos que utiliza nos projetos, essa escolha recai, ainda, sobre os artefatos preditivos. Isso parece indicar que os gerentes de projetos, talvez pelo fato de os métodos preditivos estarem há mais tempo no mercado, buscam apoiar-se em metodologias mais conhecidas no que tange ao gerenciamento do escopo do projeto. Outra suposição possível é que mesmo os gerentes de projetos que usam artefatos ágeis não os usam em sua totalidade.
Ao se calcular as médias dos percentuais dentro do grupo metodológico a que pertencem, observa-se que os artefatos preditivos são mais utilizados, tendo $62 \%$ de respostas para "sempre" e "quase sempre" para este modelo de gestão, contra $42 \%$ para os artefatos do modelo ágil (figura 3). Utilizandose o gráfico de Pareto, os artefatos também foram elencados pela ordem decrescente de quantidade de respostas "sempre" e "quase sempre" (figura 4). Entre os 10 artefatos mais utilizados, apenas o artefato "definição da arquitetura da solução" (A5) é ágil, mas, mesmo assim, aparece na sétima posição. Os cinco artefatos mais utilizados são todos 
preditivos, sendo eles: especificação do escopo do projeto (P3), entregas aceitas (P2), documentação dos requisitos (P1), linha de base do cronograma (P6) e registros das partes interessadas (P13) em ordem decrescente de utilização. Os cinco artefatos menos utilizados, por sua vez, são todos ágeis: estórias (A6), característica comercializável mínima (A4), incremento do produto (A7), backlog da timebox (A1) e metáfora (A9).

A maior utilização de artefatos preditivos pode estar relacionada, ainda, ao fato de que só recentemente houve uma eclosão dos métodos ágeis. Por exemplo, apenas em 2017 ocorreu a publicação do Guia Ágil (PMI, 2017b). Também nesta linha, foi apenas na sexta edição do PMBOK que o PMI (2017a) passou a indicar, explicitamente, a existência de métodos ágeis e a sugerir considerações adaptativas no ciclo de gestão do projeto. Mesmo com os métodos ágeis já sendo divulgados desde o Manifesto para Desenvolvimento Ágil de Software (Beck et al., 2001), observa-se que as organizações de gerenciamento de projetos apenas mais recentemente vêm publicando e divulgando essas metodologias.

Figura 3 - Médias percentuais agrupadas por metodologia

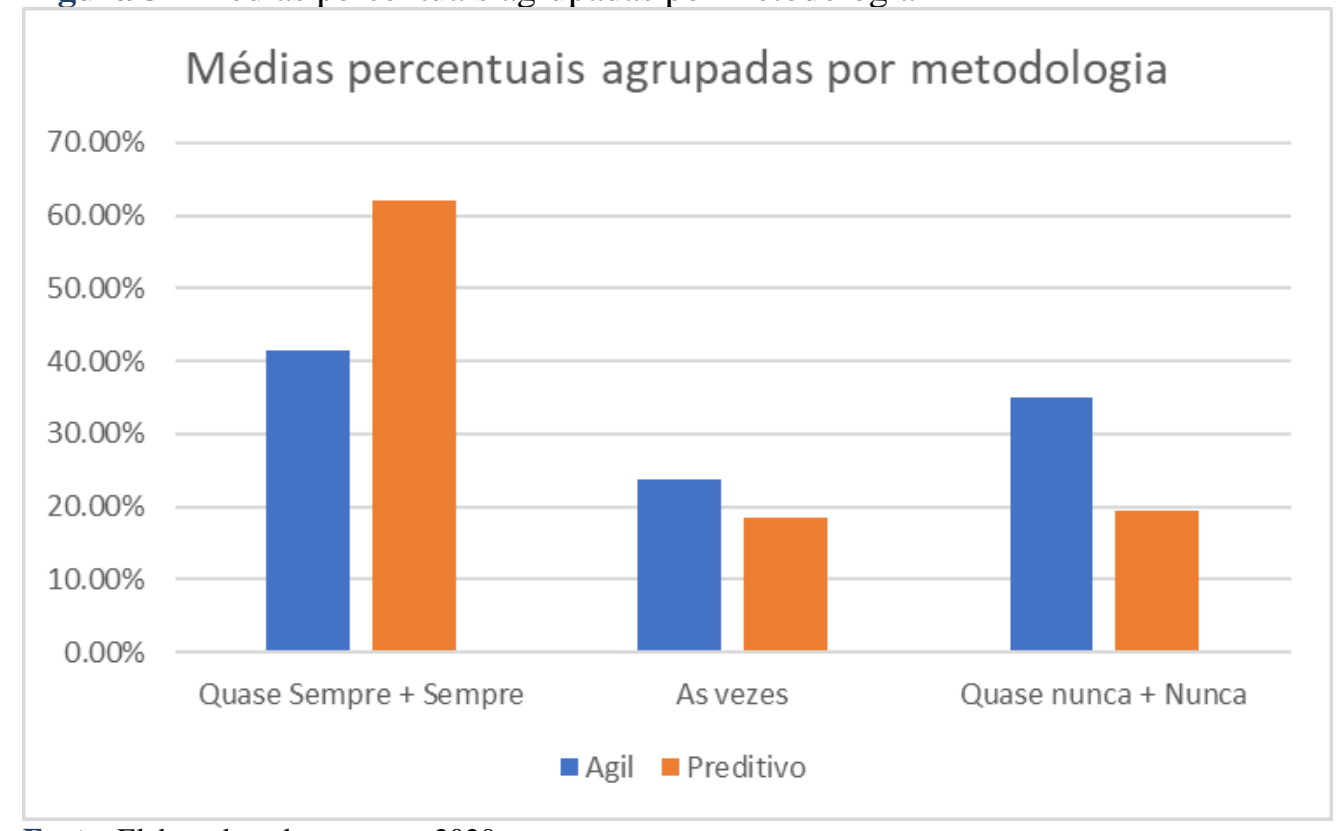

Fonte: Elaborado pelos autores, 2020.

Outro fator que pode estar relacionado à utilização inferior dos artefatos ágeis referese ao fato de que esses métodos não são aplicáveis a todos os tipos de projetos (Highsmith, 2012). Os métodos ágeis, por seu modelo de planejamento, podem ser, de certa forma, temidos pelas organizações maiores e mais governadas (Agile Business Consortium , 2014).

Para a análise da variável complexidade atribuiu-se o valor da complexidade do projeto quando a resposta era "sempre" e "quase sempre" e valor zero para as demais respostas. Analisando a média das 
complexidades para essa situação, observa-se que o artefato "metáfora" (A9), apesar de ser o artefato com a menor utilização absoluta (figura 4), é o que apresenta a maior média de complexidade (tabela 2), sendo um indicativo de que este artefato, pertencente à metodologia eXtreme Programming, é utilizado nos projetos de mais alta complexidade. Tal fato é consistente com a literatura estudada que aponta que projetos com menor clareza de solução e objetivo requerem uma gestão extrema (Wysocki, 2014). Outra observação é que os artefatos ágeis apresentam uma média de complexidade de projetos mais altas ou mais baixas. Os artefatos preditivos, por sua vez, estão concentrados no meio das médias de complexidade, com alguns se localizando nos pontos inferiores ou superiores das complexidades médias.

Figura 4 - Pareto de utilização dos artefatos



Fonte: Elaborado pelos autores, 2020 
Rabetti, D., \& Rodrigues I. (2021, Ed. Esp. jan./abr.). Gestão adaptativa de projetos: um levantamento dos artefatos mais utilizados para gerenciar o escopo do projeto

Tabela 2 - Dados consolidados por artefatos

\begin{tabular}{|c|c|c|c|c|}
\hline Artefato & $\begin{array}{c}\text { Média de } \\
\text { Complexidade } \\
\text { Sempre e Quase } \\
\text { Sempre }\end{array}$ & $\begin{array}{c}\text { Média de } \\
\text { Complexidade } \\
\text { Nunca e } \\
\text { Quase Nunca }\end{array}$ & $\begin{array}{c}\text { Quantidade de } \\
\text { Sempre e Quase } \\
\text { Sempre }\end{array}$ & $\begin{array}{l}\text { Quantidade de Nunca } \\
\text { e Quase Nunca }\end{array}$ \\
\hline P10 & 18.75 & 21 & 20 & 13 \\
\hline P11 & 18.8125 & 20.84211 & 16 & 19 \\
\hline P14 & 19.17391 & 20.25 & 23 & 4 \\
\hline A2 & 19.63158 & 19.92308 & 19 & 13 \\
\hline A1 & 19.66667 & 20.18182 & 15 & 22 \\
\hline A7 & 19.66667 & 19.81818 & 9 & 11 \\
\hline A10 & 19.80952 & 20.0625 & 21 & 16 \\
\hline A6 & 19.8125 & 20.375 & 16 & 16 \\
\hline A5 & 19.81481 & 20.4 & 27 & 5 \\
\hline P3 & 19.89189 & 20.5 & 37 & 2 \\
\hline P1 & 19.9 & 19.85714 & 30 & 7 \\
\hline P12 & 19.94444 & 20.5 & 18 & 8 \\
\hline P13 & 20 & 20.25 & 30 & 4 \\
\hline P6 & 20 & 19.6 & 29 & 5 \\
\hline P7 & 20 & 18.71429 & 26 & 7 \\
\hline P5 & 20.12 & 18.625 & 25 & 8 \\
\hline $\mathbf{P 2}$ & 20.12121 & 19 & 33 & 2 \\
\hline P8 & 20.14286 & 19.11111 & 28 & 9 \\
\hline A4 & 20.1875 & 19.30769 & 16 & 13 \\
\hline A3 & 20.28 & 19 & 25 & 4 \\
\hline P9 & 20.29412 & 20.16667 & 17 & 18 \\
\hline A8 & 20.35 & 19.7 & 20 & 10 \\
\hline P15 & 20.3913 & 18.2 & 23 & 5 \\
\hline P4 & 20.81481 & 18.125 & 27 & 8 \\
\hline A9 & 24 & 19.78788 & 2 & 33 \\
\hline
\end{tabular}

Fonte: Elaborado pelos autores, 2020.

De forma análoga, para a análise da variável complexidade atribuiu-se o valor da complexidade do projeto considerando-se as respostas "nunca" e "quase nunca" para calcular a média de complexidade dos projetos por artefato. Pode-se verificar que os artefatos que apresentavam altas médias de complexidade para "sempre" e "quase sempre", passaram a apresentar médias de complexidade baixas para "nunca" e "quase nunca". Esses dados parecem apontar na direção de que existem artefatos mais indicados para serem utilizados em projetos mais complexos, e artefatos indicados para projetos menos complexos. A tabela 2 apresenta os dados completos. 
Tabela 3 - Passos de agregação para artefatos para respostas Sempre e Quase Sempre

\begin{tabular}{|c|c|c|c|c|c|c|c|}
\hline \multirow{2}{*}{$\begin{array}{c}\text { Passo } \\
1 \\
\end{array}$} & \multirow{2}{*}{$\begin{array}{l}\text { Número } \\
\text { de Grupos } \\
24\end{array}$} & \multirow{2}{*}{$\begin{array}{l}\begin{array}{l}\text { Nível de } \\
\text { similaridade }\end{array} \\
90.823 \\
\end{array}$} & \multirow{2}{*}{\begin{tabular}{|r|}
$\begin{array}{l}\text { Nível de } \\
\text { distância }\end{array}$ \\
1378.0 \\
\end{tabular}} & \multicolumn{2}{|c|}{$\begin{array}{l}\text { Grupos } \\
\text { agregados }\end{array}$} & \multirow{2}{*}{$\begin{array}{l}\begin{array}{l}\text { Novo } \\
\text { Grupo }\end{array} \\
19\end{array}$} & \multirow{2}{*}{$\begin{array}{l}\text { Número de obs. } \\
\text { no novo grupo } \\
2\end{array}$} \\
\hline & & & & 19 & 20 & & \\
\hline 2 & 23 & 83.904 & 2417.0 & 12 & 13 & 12 & 2 \\
\hline 3 & 22 & 83.624 & 2459.0 & 1 & 18 & 1 & 2 \\
\hline 4 & 21 & 83.205 & 2522.0 & 7 & 8 & 7 & 2 \\
\hline 5 & 20 & 79.582 & 3066.0 & 9 & 10 & 9 & 2 \\
\hline 6 & 19 & 78.609 & 3212.0 & 16 & 17 & 16 & 2 \\
\hline 7 & 18 & 76.119 & 3586.0 & 2 & 9 & 2 & 3 \\
\hline 8 & 17 & 75.275 & 3712.7 & 7 & 15 & 7 & 3 \\
\hline 9 & 16 & 72.296 & 4160.0 & 5 & 6 & 5 & 2 \\
\hline 10 & 15 & 71.477 & 4283.0 & 12 & 14 & 12 & 3 \\
\hline 11 & 14 & 70.338 & 4454.0 & 3 & 24 & 3 & 2 \\
\hline 12 & 13 & 66.999 & 4955.5 & 2 & 21 & 2 & 4 \\
\hline 13 & 12 & 66.380 & 5048.3 & 7 & 11 & 7 & 4 \\
\hline 14 & 11 & 57.865 & 6327.0 & 22 & 23 & 22 & 2 \\
\hline 15 & 10 & 54.701 & 6802.1 & 7 & 12 & 7 & 7 \\
\hline 16 & 9 & 53.574 & 6971.3 & 3 & 25 & 3 & 3 \\
\hline 17 & 8 & 47.254 & 7920.3 & 3 & 5 & 3 & 5 \\
\hline 18 & 7 & 46.597 & 8019.0 & 16 & 19 & 16 & 4 \\
\hline 19 & 6 & 42.215 & 8677.1 & 3 & 4 & 3 & 6 \\
\hline 20 & 5 & 42.105 & 8693.5 & 1 & 2 & 1 & 6 \\
\hline 21 & 4 & 31.573 & 10275.0 & 16 & 22 & 16 & 6 \\
\hline 22 & 3 & 12.790 & 13095.5 & 3 & 16 & 3 & 12 \\
\hline 23 & 2 & -17.986 & 17716.8 & 3 & 7 & 3 & 19 \\
\hline 24 & 1 & -137.459 & 35656.8 & 1 & 3 & 1 & 25 \\
\hline
\end{tabular}

Fonte: Elaborado pelos autores, 2020.

Ainda no que tange a complexidade, foi observado que os projetos usados como base para resposta pelos gestores de projetos se concentraram praticamente do meio da escala para seu final, escala essa que vai de 7 a 28 . Não houve nenhum projeto com a complexidade máxima. A amostra apresentou moda de 18 e a média e mediana foram ambas iguais a 20. A menor complexidade observada foi de 15, com três ocorrências e a maior complexidade, também com três ocorrências foi de 25 (figura 5). 
Silveira, T. B. J., \& Lemos, D. da C. (2021, Ed. Esp. jan./abr.). Colaboração com clientes e inovação aberta no desenvolvimento àgil de software: uma revisão sistemática de literatura

Figura 5 - Distribuição da complexidade dos projetos

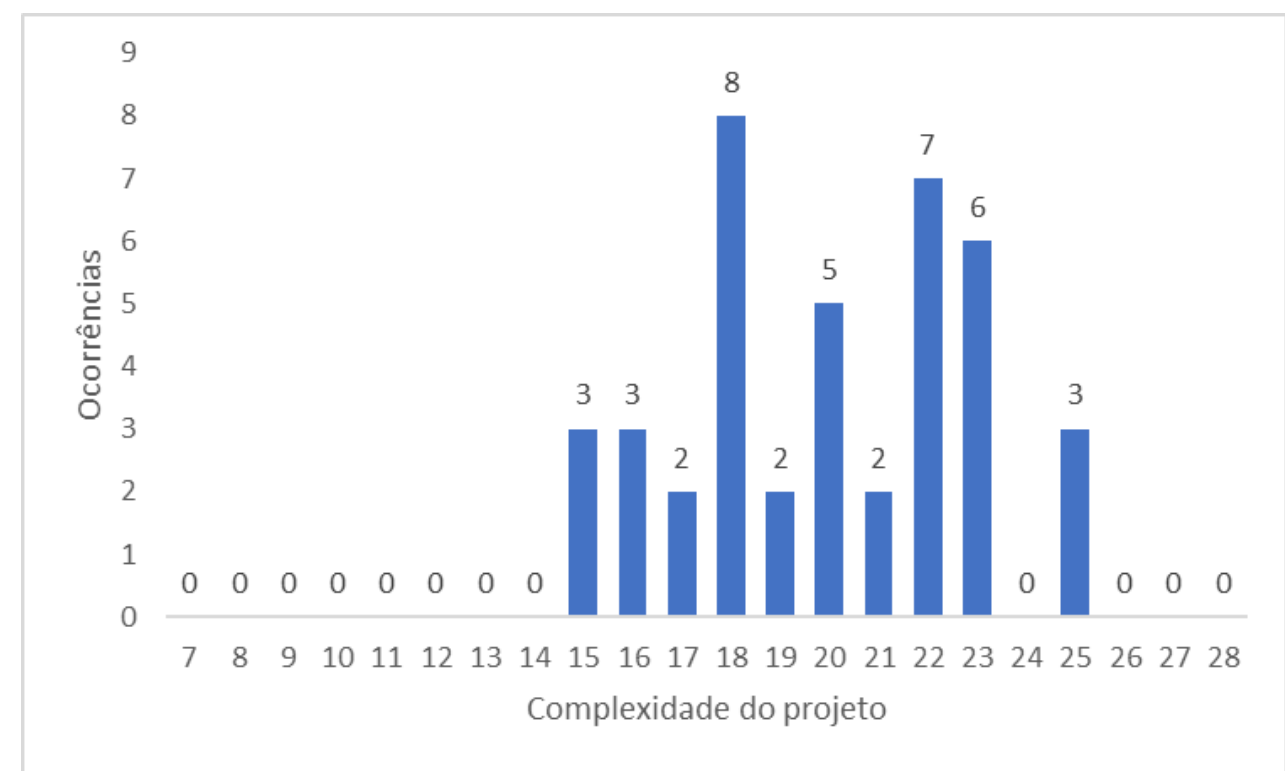

Fonte: Elaborado pelos autores, 2020.

Para determinação dos agrupamentos de artefatos, como descrito no item dedicado ao método, mediante o uso do software Minitab, foi adotada como parâmetro a criação de quatro agrupamentos, cujo dentograma é apresentado na figura 6 e os respectivos passos para agregação na tabela 3 . 
Silveira, T. B. J., \& Lemos, D. da C. (2021, Ed. Esp. jan./abr.). Colaboração com clientes e inovação aberta no desenvolvimento àgil de software: uma revisão sistemática de literatura

Figura 6 - Agrupamentos para respostas Sempre e Quase Sempre

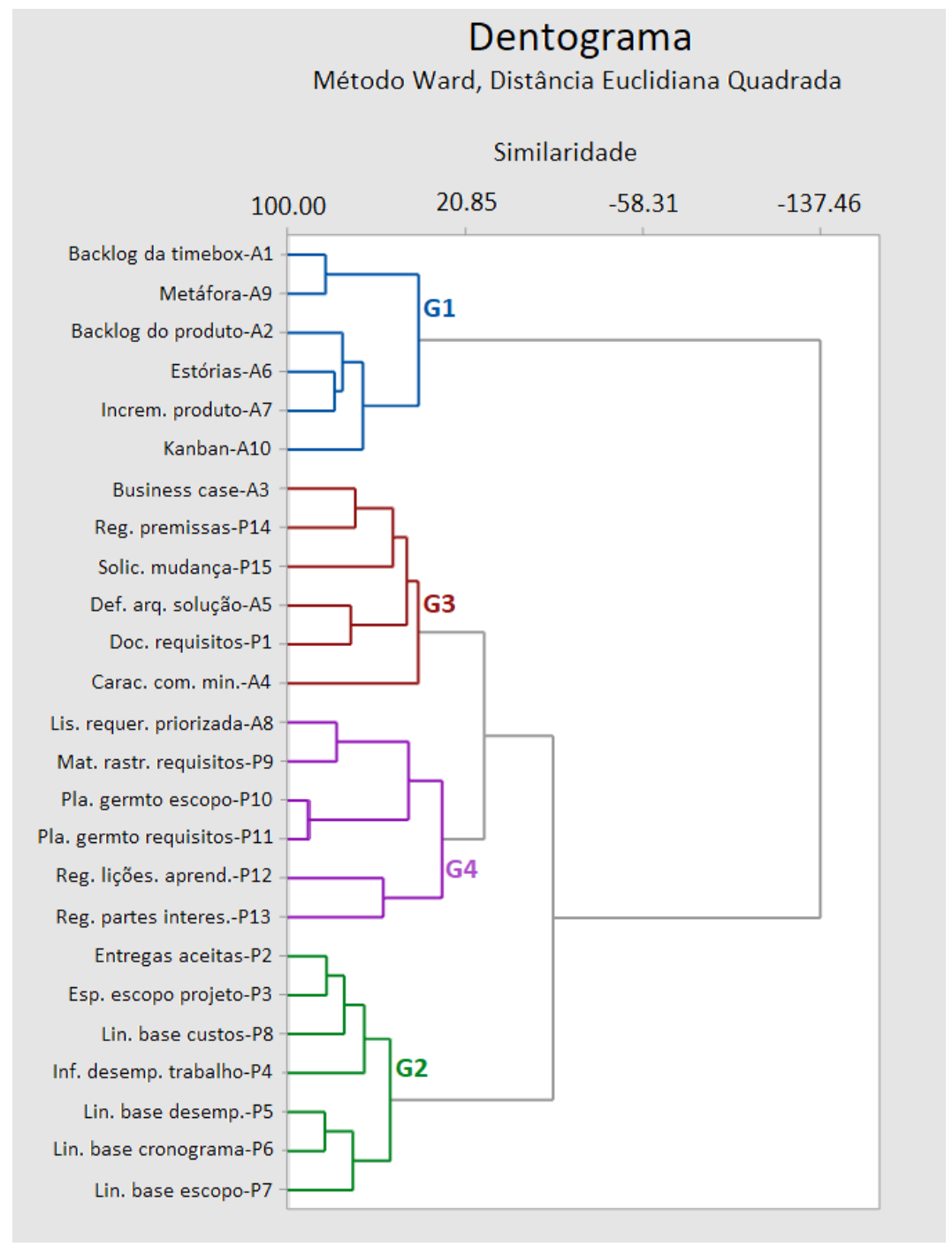

Fonte: Elaborado pelos autores, 2020.

Tabela 4 - Estatísticas descritivas da complexidade dos projetos por agrupamentos

\begin{tabular}{c|l|l|l|l|l|l|l|l|l}
\hline Variável & Agrupamento & $\mathbf{N}$ & Média & $\begin{array}{c}\text { Desv. } \\
\text { Padrão }\end{array}$ & Mínimo & Q1 & Mediana & Q3 & Máximo \\
\hline \multirow{3}{*}{ Complexi-dade S QS } & G1 & 6 & 20.431 & 1.750 & 19.632 & 19.658 & 19.738 & 20.859 & 24.000 \\
\cline { 2 - 11 } & G2 & 7 & 20.156 & 0.304 & 19.892 & 20.000 & 20.120 & 20.143 & 20.815 \\
\cline { 2 - 11 } & G3 & 6 & 19.958 & 0.443 & 19.174 & 19.655 & 20.044 & 20.308 & 20.391 \\
\cline { 2 - 10 } & G4 & 6 & 19.692 & 0.723 & 18.750 & 18.797 & 19.972 & 20.308 & 20.350 \\
\hline
\end{tabular}

Fonte: Elaborado pelos autores, 2020.

Analisando-se $\mathrm{o}$ resultado do agrupamento, observa-se que no primeiro agrupamento (G1) há apenas artefatos ágeis, enquanto que no segundo agrupamento (G2) há apenas artefatos preditivos. Um terceiro agrupamento (G3) se mostrou equilibrado, com três artefatos de cada metodologia. O quarto agrupamento (G4) apresentou predominância preditiva, com apenas um artefato ágil.

O fato do agrupamento G4 conter apenas um artefato ágil pode estar mais 
relacionado ao desbalanceamento de quantidade de artefatos analisados: 15 preditivos e apenas 10 ágeis. Podemos observar pelo dentograma, inclusive, que os grupos G3 e G4 formam o próximo agrupamento, de forma que temos um agrupamento ágil (G1), um agrupamento preditivo (G2) e um continuum entre os dois, composto pelos agrupamentos G3 e G4.

Calculando-se as médias da complexidade dos artefatos de cada agrupamento observa-se que não há diferenças significativas sobre a média, porém observa-se que o agrupamento formado apenas pelos artefatos ágeis (G1) apresenta uma concentração para complexidades maiores, visto que há uma assimetria em direção ao terceiro quartil. No grupo formado apenas por artefatos preditivos (G2) observa-se que a distribuição é bem mais simétrica, além do desvio padrão ser bem reduzido (tabela 4 e figura 7). Isso nos demonstra que, como elencado na introdução, os modelos preditivos se mostram mais oportunos para ambientes mais estáveis, com clareza de objetivos e soluções, ao passo que os ágeis estariam mais propensos aos ambientes mais voláteis, com maior variabilidade e, consequentemente, maior risco para projeto (Maximiano, 2007; Wysocki, 2014).

Figura 7 - Boxplot de complexidade do projeto por agrupamento

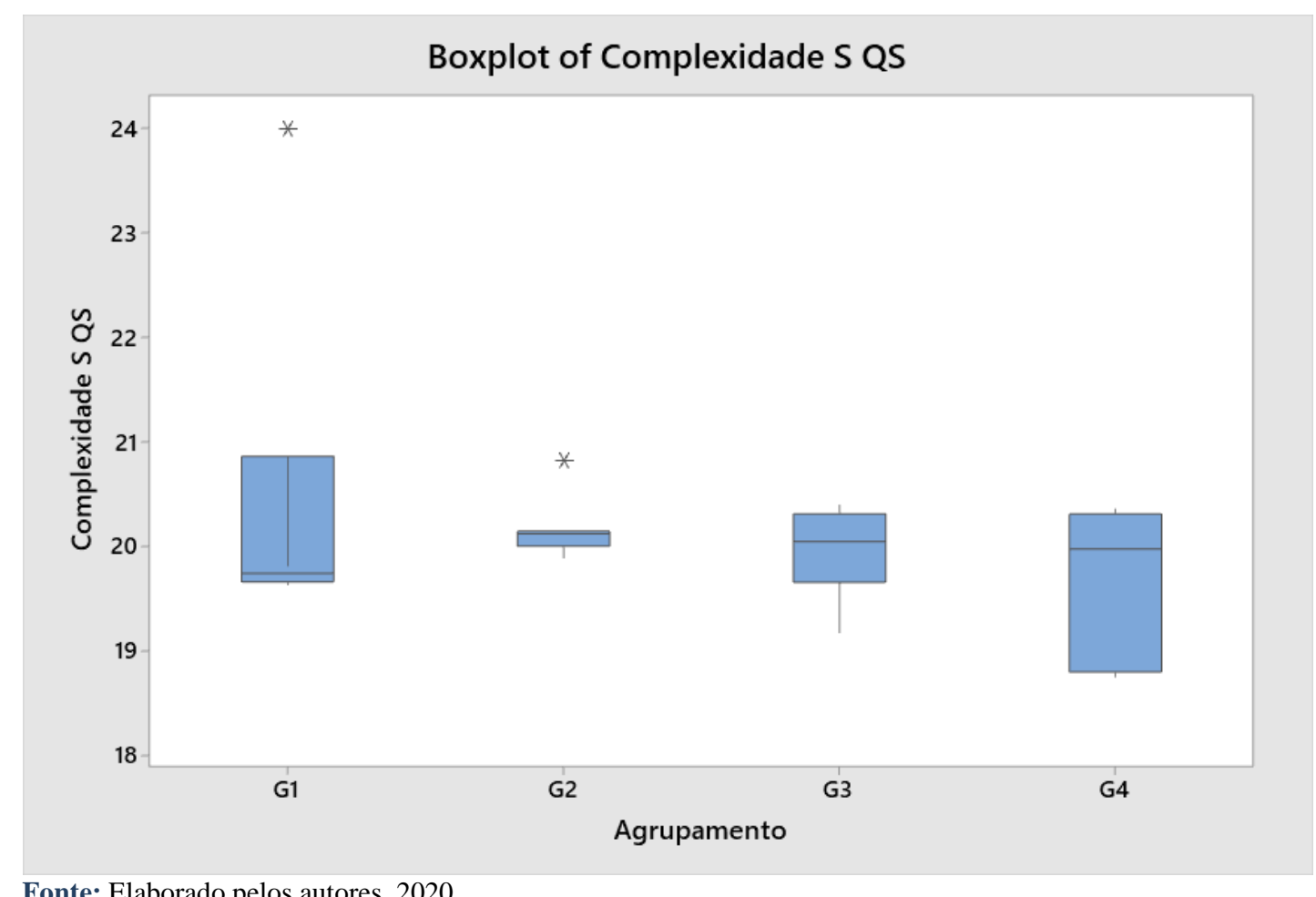

Fonte: Elaborado pelos autores, 2020.

Comportamento similar ao do G2 ocorre com o grupo misto (G3), com a exceção de que esse possui um distanciamento maior da mediana para os quartis, ou seja, há um aumento na variabilidade das complexidades dos projetos. Mais uma vez, observa-se que, 
possivelmente, os gerentes de projetos tender a usar artefatos preditivos e ágeis como forma de adaptação às necessidades do projeto (Cooper \& Sommer, 2016; Shenhar \& Dvir, 2010).

Similar ao grupo totalmente ágil (G1), o G4, que contém apenas um artefato ágil, também apresenta uma assimetria na distribuição, porém na direção do primeiro quartil, ou seja, para complexidades menores. Porém, como já alertado anteriormente, também nesse caso isso pode estar relacionado às diferentes quantidades de artefatos ágeis e preditivos estudados. Portanto, é possível analisar os agrupamentos G3 e G4 de uma forma conjunta no contexto do continuum entre o ágil e o preditivo e assim observar que um tipo de gestão não atende a todos (Shenhar, 2001).

\section{Conclusões}

Acerca da influência das organizações na tomada de decisões dos gerentes de projetos na seleção dos artefatos de acordo com o tipo de projeto, como discutido na análise dos dados, observou-se que as empresas ainda determinam em sua maioria quais os artefatos os gestores de projetos devem utilizar. Contudo, já consideram diferentes artefatos para diferentes tipos de projetos e há indícios de que as empresas estão caminhando para um aumento na liberdade de escolha dos artefatos pelo gestor de projetos e migração para uma metodologia adaptativa de gestão de projetos, ou por determinar diferentes artefatos para diferentes projetos, ou por permitir a seleção dos artefatos pelo gestor de acordo com a sua necessidade.

Vemos que os artefatos preditivos são os mais utilizados, com apenas um artefato ágil entre os dez primeiros. Desta forma, observase que, apesar das empresas estarem mostrando uma tendência de abertura na gestão, há ainda um predomínio na utilização do modelo preditivo de gestão de projetos. Esse predomínio dos artefatos preditivos pode estar relacionado ao relativo pouco tempo em que as metodologias ágeis estão sendo utilizadas e menor tempo ainda que foram, de certa forma, reconhecidas pelas organizações de gerenciamento de projetos. Outro aspecto que pesa contra as metodologias ágeis é o fato de que, por elas não terem o planejamento todo no início do projeto, as empresas com maior aversão ao risco não a adotariam, pois quanto mais desconhecido maior o risco.

Com relação à influência da complexidade do projeto na escolha dos artefatos de gestão de escopo do projeto, pudemos observar que existem indícios de que os artefatos ágeis são mais aplicáveis para projetos de maior complexidade. Também há indícios de que os artefatos preditivos, apesar de também serem usados em projetos complexos, são usados em projetos com uma variação menor de complexidade. Também podemos concluir que existe um grupo misto de artefatos ágeis e preditivos que apresentam a sua utilização em uma faixa de projetos intermediária de complexidade dos projetos, 
ou seja, que existe um continuum entre as abordagens preditivas e ágeis.

A pesquisa contribuiu na consolidação teórica dos artefatos utilizados para a gestão de escopo de projetos, tanto na corrente preditiva, quanto nos diversos frameworks ágeis de gestão de projetos. Observou-se que a gestão preditiva de projetos contém mais artefatos de gerenciamento de escopo (15) que a metodologia de gestão ágil (10 artefatos). Como implicações gerenciais, aponta-se a importância de os gestores serem flexíveis quando da adoção de artefatos de gestão de escopo, bem como a necessidade de analisar quais desses artefatos são mais adequados em função da complexidade do projeto.

Este estudo apresenta duas limitações, ambas relacionadas ao tamanho da amostra. A primeira refere-se ao número de respondentes que não permitiu análises estatísticas mais complexas. Portanto, a pesquisa limita-se a indicar indícios. A segunda limitação é quanto à análise de complexidade que não pode avançar nos fatores de complexidade isoladamente. Há, portanto, oportunidades de pesquisas futuras que analisem quais os fatores da variável complexidade interferem na escolha de cada um dos artefatos, sendo para isso necessária uma amostra de dez respostas para cada variável, como indicado por Hair et al (2005). Outras pesquisas também podem explorar o tipo de análise realizada aqui para os artefatos de escopo para outras áreas de conhecimento, como a gestão de partes interessadas que também é uma área de conhecimento de grande relevância tanto para a metodologia preditiva quanto ágil de gestão de projetos. Sugere-se, por fim, estudos que analisem como a cultura organizacional pode afetar a adoção de métodos híbridos.

\section{Referências}

Agile Business Consortium (2014). Agile Project Framework Handbook. Recuperado em 14 de julho, 2019, de:

https://www.agilebusiness.org/page/ProjectF ramework_00_welcome.

Alba, J., Cron, D., El Ouarti, M., Pugliese, G., Schmehr, W., Simonelli, L., \& Wolstad, J. (2016). IPMA International Certification Regulations. International Project Management Association (IPMA).

Appelo, J. (2011). Management 3.0: leading agile developers, developing agile leaders. Boston: Pearson Education.

\section{AXELOS. (2018). What is PRINCE2?}

Recuperado 9 de abril de 2018, de https://www.prince2.com/usa/what-isprince 2

Babbie, E. R. (1999). Métodos de pesquisa de survey. Belo Horizonte, UFMG.

Batra, D.; Xia, W.; Vandermeer, D. \& Dutta, K (2010). Balancing agile and structured development approaches to successfully manage large distributed software projects: a case study from the cruise line industry. Communications of the Association for Information Systems (CAIS), Vol. 27, Article 21.

Beck, K, Beedle., Bennekum, A. Van, Cockburn, A., Cunningham, W., Fowler, M., Grenning, J., Highsmith, J., Hunt, A., Jeffries, R., Kern, J., Marick, B., Martin, C., Mellor, S., Schwaber, K., Sutherland, J. (2001). Manifesto para Desenvolvimento Ágil de Software. Recuperado 22 de março de 2018 de 2001 de website: 
http://agilemanifesto.org/iso/ptbr/manifesto. html.

Conforto, E. C. \& Amaral, D. C. (2007) Escritório de Projetos e Gerenciamento Ágil: um novo enfoque para a estrutura de apoio à gestão de Projetos Ágeis. Anais. XXVII Encontro Nacional de Engenharia de Produção (Enegep). Foz do Iguaçu, Paraná, Brasil.

Conforto, E. C. \& Amaral, D.C. (2008). Evaluating an Agile Method for Planning and Controlling Innovative Projects. Project Management Journal, Vol. 41, No. 2, p. 7380.

Cooper, R. G. \& Sommer, A. F. (2016) Promising New Approach and a New Research Opportunity. v. 33, n. 5, pp. 513526.

Cooper, R. G. \& Sommer, A. F. (2020). NewProduct Portfolio Management with Agile. Research-Technology Management, 63(1): 29-38.

Dao, B., Kermanshachi, S., Shane, J., Anderson, S., \& Hare, E. (2016). Identifying and Measuring Project Complexity [Eletronic version]. Procedia Engineering, 145, 476-482.

Forza, C. (2002). Survey research in operations management: A process-based perspective. International Journal of Operations and Production Management, v. 22, n. 2, pp. 152-194, 2002.

Global Alliance for the Project Professions (2007). A framework for performance based competency standards for global level 1 and 2 project managers. Global Alliance for Project Performance Standards.

Geraldi, J.; Maylor, H. \& Williams, T. (2011) General rights Now, let's make it really complex (complicated): A systematic review of the complexities of projects. Recuperado em 22 de setembro, 2019, de https://doi.org/10.1108/01443571111165848
Hair, J. F., Jr., Anderson, R. E., Tatham, R. L., \& Black, W. C. (2005). Análise

Multivariada de Dados. (5. ed.). Bookman.

Highsmith, J. (2012). Gerenciamento Ágil de Projetos: Criando Produtos Inovadores. 2. ed. ed. Rio de Janeiro, RJ: Alta Books.

Hollingsworth, C. (2011). What kanban can do. PM Network, 25(3), 66-67.

Kerzner, H. (2013). Project Management Metrics, KPIs, and Dashboards: a guide to measuring and monitoring project performance. 2. ed. ed. Hoboken: Wiley.

Leach, L. P. (2005). Lean project management: eight principles for success. Boise, Idaho: Advanced-projects.

Maximiano A. C. A. (2007). Administração de projetos: como transformar ideias em resultados. $2^{\text {a }}$. ed. São Paulo: Atlas.

Papadakis, E. \& Tsironis, L. K. (2020) Towards a Hybrid Project Management Framework: A Systematic Literature Review on Traditional, Agile and Hybrid Techniques. Journal of Modern Project Management, [s. 1.], v. 08, n. 2, p. 124-139.

PMI (2014). Navigating complexity: a practice guide. Newtown Square: Project Management Institute (PMI).

PMI (2017a). Guia do Conhecimento em Gerenciamento de Projetos. 6. ed. ed. Newtown Square, PA: Project Management Institute (PMI).

PMI (2017b). Guia Ágil. Newtown Square, PA: Project Management Institute (PMI).

Poveda-Bautista, R., Diego-Mas, J. A., \& Leon-Medina, D. (2018). Measuring the Project Management Complexity: The Case of Information Technology Projects. Complexity [Eletronic Version], 2018. https://doi.org/10.1155/2018/6058480.

Sampieri, R. H., Collado C. F. \& Lucio, M. D. P. B. (2013). Metodologia de Pesquisa. Porto Alegre: Penso. 
Sauer, S. (2017). Agile Project Management as a generator of stress relief and efficiency? International Journal of Strategic Management, v. 17, n. 2, p. 67-74.

Schwaber, K. \& Sutherland, J. (2017) Scrum Guides Downloads. Recuperado em Disponível em 21 de novembro, 2019, de: <http://www.scrumguides.org/docs/scrumgu ide /v2017/2017-Scrum-Guide-PortugueseBrazilian.pdf>.

Shenhar, A. J., Milosevic, D., Dvir, D., \& Thamhain, H. (2007). Linking Project Management to Business Strategy. Newtown Square, PA: Project Management Institute (PMI).

Shenhar, A. J. (2001) One size does not fit all projects: Exploring Classical Contingency Domains. Management Science, v. 47, n. 3 , p. 394-414.

Shenhar, A. J. \& Dvir, D. (2010) Reinventando gerenciamento de projetos: a abordagem diamante ao crescimento e inovação bemsucedidos. São Paulo: M.Books.

Souza Pinto, J., Novaski, O., Anholon, R., \& Carpim Besteiro, É. N. (2014). Proposta de Método de Mensuração da Complexidade em Projetos [Versão eletrônica]. Revista de Gestão e Projetos, 5(3), 14-29. https://doi.org/10.5585/gep.v5i3.280.

Spundak, M. (2014). Mixed agile/traditional project management methodology - reality or illusion? Procedia - Social and Behavioral Sciences. No. 119, pp. 939-948.

Valeriano, D. L. (2001). Gerenciamento estratégico e administração por projetos. Makron Books. São Paulo, SP.

Valle, A. B., Soares, C. A. P., Finocchio Jr., J \& Silva, L. S. F. (2010). Fundamentos do gerenciamento de projetos (2a ed.). Editora FGV.

Vidal, L. A.; Marle, F. \& Bocquet, J. C. (2011) Measuring project complexity using the Analytic Hierarchy Process. International Journal of Project Management, v. 29, n. 6, p. 718-727.
Wysocki, R. K. (2014). Effective project management: traditional, agile, extreme. 7. ed. ed. New Delhi: Wiley.

Yugue, R. T. \& Maximiano, A. C. A. (2013). Entendendo e gerenciando a complexidade de projetos. Revista de Gestão e Projetos GeP, São Paulo, v. 4, n. 1, p 01-22, jan./abr.

Zasa, A. P. \& Pellizzoni, E; (2021). Managing the Hybrid Organization: How Can Agile and Traditional Project Management Coexist? Research-Technology Management, January-February. 